\title{
Flexible new optics facilities with electronics and computer systems integration in a renovated building at a smaller state university
}

Ralph Oberly, James Brumfield

Ralph E. Oberly, James O. Brumfield, "Flexible new optics facilities with electronics and computer systems integration in a renovated building at a smaller state university," Proc. SPIE 1603, Education in Optics, (1 March 1992); doi: 10.1117/12.57839 
Flexible new optics facilities with electronics and computer systems integration in a renovated building at a smaller state university

Ralph Oberly and James 0. Brumfield

College of Science, Marshall University Huntington, WV 25755 USA

\begin{abstract}
A renovated facility is being used for a broad-based and flexible approach to teaching optics and optical systems at the undergraduate and M.S. levels. The range of topics included in the curriculum is from conventional geometrical and physical optics to laser physics, optical transformations, electro-optical devices, remote sensing and digital image processing. Emphasis of this paper is on the design and use of the new facilities, and the interrelationships of the various areas presented. The optics complex contains conventional optics teaching laboratory space with soft walls, an electronics teaching laboratory, a holography laboratory with darkroom, and a remote sensing computer simulation modeling and digital image processing laboratory. Moreover, a machine vision facility is a computer networked extended part of the digital image processing systems in an operational mode involving interfaced flexible machine cells. These cells are robotics interfaced in a flexible manufacturing system that is capable of process and machine part prototyping computer networked with a CAD system.
\end{abstract}

\title{
2. INTRODUCTION
}

The Science Building at Marshall University, within the University of West Virginia, is being completely remodeled to provide up-to-date instructional and research facilities for the students and faculty of the University. The building houses the Departments of Geology, Chemistry, Biological Sciences, and Physics and Physical Sciences. The renovation project includes a 6130 square meters $(66,000$ square feet) addition and the total renovation of an existing four story structure that contains 11,900 square meters ( 127,960 square feet). A significant part of the renovated space has been designed with the intent of providing a flexible space for instruction and research in the topic areas of optics, electronics, electro-optics, and computer simulation modeling.

Before going into any detail on the design of the new facilities, a few details on Marshall University and the offerings of the Department of Physics and Physical Science will be given. Marshall is a part of the University of West Virginia and has a student population of roughly 12,000 on this campus. The Department of Physics and Physical Science offers a B.S. degree in physics with a conventional classical mechanics, electricity and magnetism, thermodynamics, and modern/quantum physics core curriculum. Additional courses are 
available as electives to the physics majors that enable the students to broaden their scientific and technical backgrounds. In par-

ticular, the areas of optical, electronic and nuclear physics have been viewed as especially vital for student career development. The major part of this paper will be devoted to the facilities for the optics, electronics, electro-optics and computer simulation modeling portion of the curriculum.

In addition to the physics B.S. curriculum there is a track at the baccalaureate level for the training of secondary school physics teachers. Optics and electronics play central roles in the curriculum. At the graduate level the degree program is currently limited to an M.S. degree in physical science. This program with a science education emphasis is designed to broaden and enrich the science backgrounds of active science teachers. As such it provides an "in field" alternative to the usual school administration programs that take some science teachers out of the classroom. This alternative allows teachers to take courses in physics, astronomy, geology, chemistry, mathematics, and computer science that directly strengthen their knowledge of science and their teaching skills in the science classroom. Again, the optics and electronics components are vital parts of their curriculum. This program in fact allows science teachers with certification in areas other than physics to work on physics certification while earning graduate credit. The department faculty have long agreed that secondary school science instruction within the state and region must be strengthened in order for Marshall to have students properly prepared for baccalaureate level science work. The department faculty devotes a great deal of time to this end.

A listing of relevant courses in waves, optics, electronics, electrooptics, and computer simulation modeling for all of the physics and physical science degrees follows:

-Optics/Optics Laboratory

-Optics with Life Science and Medical Applications

-Optics for Teachers

-Optics Technology

-Atomic Physics/Atomic Physics Laboratory

-Modern/Quantum Physics

-Laser Principles

-Electro-optics

-Electronic Physics/Electronics Laboratory

-Applied Electronics and Instrumentation

-Electronics for Teachers

-Digital Electronics

-Physics of High-Fidelity

- Physics of Remote Sensing with Applications

-Digital Image Processing and Computer Simulation Modeling

-Atmospheric Physics with Computer Simulation Modeling

Most of the above courses are official courses for the department. A few, such as Optics Technology and Physics of High-Fidelity, have only been offered on demand for selected groups. In all courses the 
parallels between optics and electronics are stressed and topics like Fourier transforms are discussed as common mathematical tools.

Another track within the physical science graduate degree program that has evolved over the past few years utilizes many of the same courses pertaining to waves, optics, electronics, 1 asers, and remote sensing/image processing, which have been taught within the department. With selection from these courses as a curriculum foundation, computer science, mathematics, geography, geology, and biological sciences can be utilized for multidisciplined thesis research preparation. This is accomplished with consultation and approval of the graduate thesis committee for the M.S. in physical science. Therefore, each student's graduate program in physical science is individually designed to meet his/her research needs. This broadens the opportunities for thesis foundations and information needs in research. Thesis research in this physical science track, whether basic or applied, involves a multidisciplined integrated program. It can include topics from electro-optic sensors and machine vision to earth observation systems and resource management with global climate models.

\section{OPTICS, ELECTRONICS, AND COMPUTER SIMULATION MODELING FACILITIES}

In the past upper division courses in this department have been taught in cramped spaces with insufficient space, control of lighting, electrical service, plumbing, ventilation, and suitable equipment. These severe conditions and the prospects of a fully renovated facility prompted the faculty to consider the following criteria for the renovated space:

1. modular spaces with individual control of lighting and other utilities,

2. accessibility among facilities involving optical, and/or computer data links,

3. integrated electronics and optics facilities designed to provide long light paths,

4. data jacks available throughout the facilities connecting to the campus-wide computer network, and

5. above objectives designed for finite existing space.

The design of the optics, electronics, and the computer simulation modeling areas resulted from a series of interactive discussions between the architectural firm (Abramovitz, Kingsland \& Schiff (AKS) of New York, prime architect G. Schiff) and the faculty. It was clear from the beginning of the design that floor space could not be dedicated for each possible project. Each space would have to serve multiple uses because of the finite size of the building to be renovated and the competing demands from four of the academic departments within the College of Science.

One corner of the building was designed for the optics, electronics, and computer simulation modeling project which was developed within the criteria listed above. The result, figure l, includes a single closed optics space for doing holography and other experiments with 


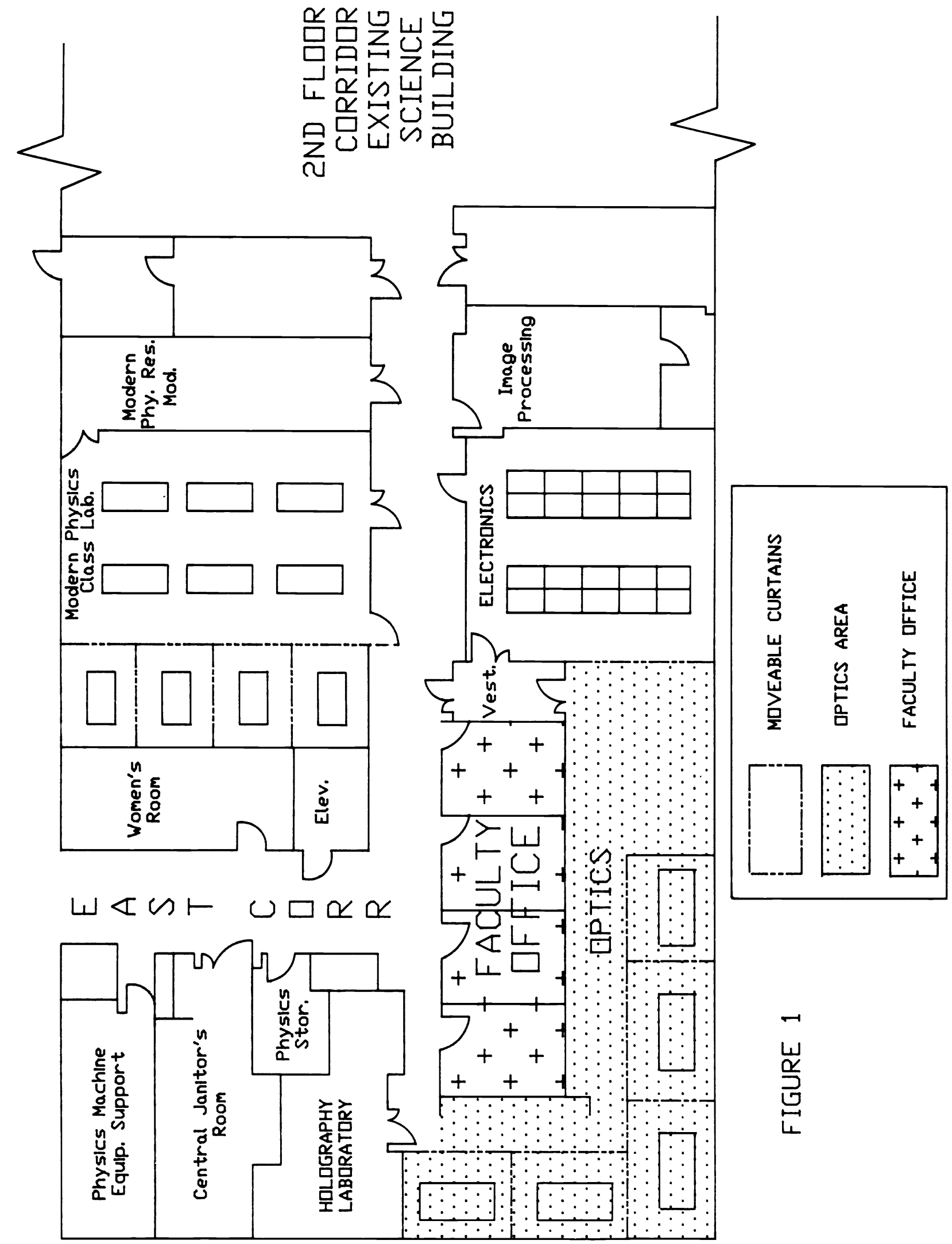

140 / SPIE Vol. 1603 Education in Optics (1991) 
higher power lasers. This space has an attached darkroom with separate amber and green safety lights. (Previously, film processing had been done in an unventilated toilet!) Extending from the holography room and around the corner of the building are a series of five curtained spaces ranging in size from $2.5 \mathrm{~m} x 3.4 \mathrm{~m}$ to $3.1 \mathrm{~m} \times$ $5.0 \mathrm{~m}$. The curtained spaces can be used for conventional spectroscopy experiments, optical image processing, fiber optics measurements, lens aberration measurements, interferometric measurements, electro-optical sensor systems experiments and so forth. Each space is enclosed on one to three sides by heavy double layered curtains that allow the space to be closed off for an experiment involving a small space, or to be expanded to a size appropriate to an experiment demanding greater space. At the other end of the curtained area is a small optics room with four laboratory tables that hold items like refractometers, measuring microscopes and small optical benches. A solid wall with an open passage aisle separates the last curtained area from the space with four tables. This space in turn is connected to the electronics laboratory with a wide folding curtain providing open access between the spaces. The electronics area has bench space for twenty students and can be darkened. Thus the connected areas can be opened up to allow an unfolded $27 \mathrm{~m}$ ( $89 \mathrm{ft}$ ) 1 ight path, figure 2, from one end of the building to the far wall of the electronics space.

The soft-walled spaces have heavy double-layered curtains that slide along tracks mounted on a bulkhead with the lower surface $2.6 \mathrm{~m}$ above the floor, figure 3. Where one curtain track ends away from a wall, there is always overlap with another curtain. On the outside walls there is a permanent attachment of the curtain to the wall. At one support pillar within the space Velcrostrips allow for sufficient light-tight attachment of the curtain to the pillar. A valance on each side of the main curtain dropping $70 \mathrm{~cm}$ from the bulkhead blocks light passage through the track area of the curtain, figure 4. The separation of the curtain track and each valance is $15.5 \mathrm{~cm}$. This system provides sufficient light isolation that experiments using photographic film can be conducted in the curtained rooms.

A ventilation duct passing through the bulkhead $(30 \mathrm{~cm} \times 30 \mathrm{~cm})$ is provided in each curtained area for ventilation air egress to prevent curtain flutters. This duct is provided with a louvered grill on one side and two baffles, each covering slightly over half of the duct area. The inside of the duct is painted flat black to minimize light reflections. Again, light isolation is sufficient to allow film to be used in the spaces.

Currently the facilities have apparatus for studying simple lenses and mirrors, lens resolution, aberrations, the prism spectrometer, index of refraction measurements, student modular interferometer, fiber optics parameters, the diffraction grating spectrometer, the Czerny-Turner monochromator, Fourier optical transforms, holography (transmission, reflection, HNDT, etc.), optical modulation, and simple polarization effects, figure 5. The major equipment items include a $0.5 \mathrm{~m}$ Czerny-Turner monochromator, a $2.0 \mathrm{~W}$ Ar-ion laser with etalon, a multiline Ar-ion laser, a tunable dye laser with a 


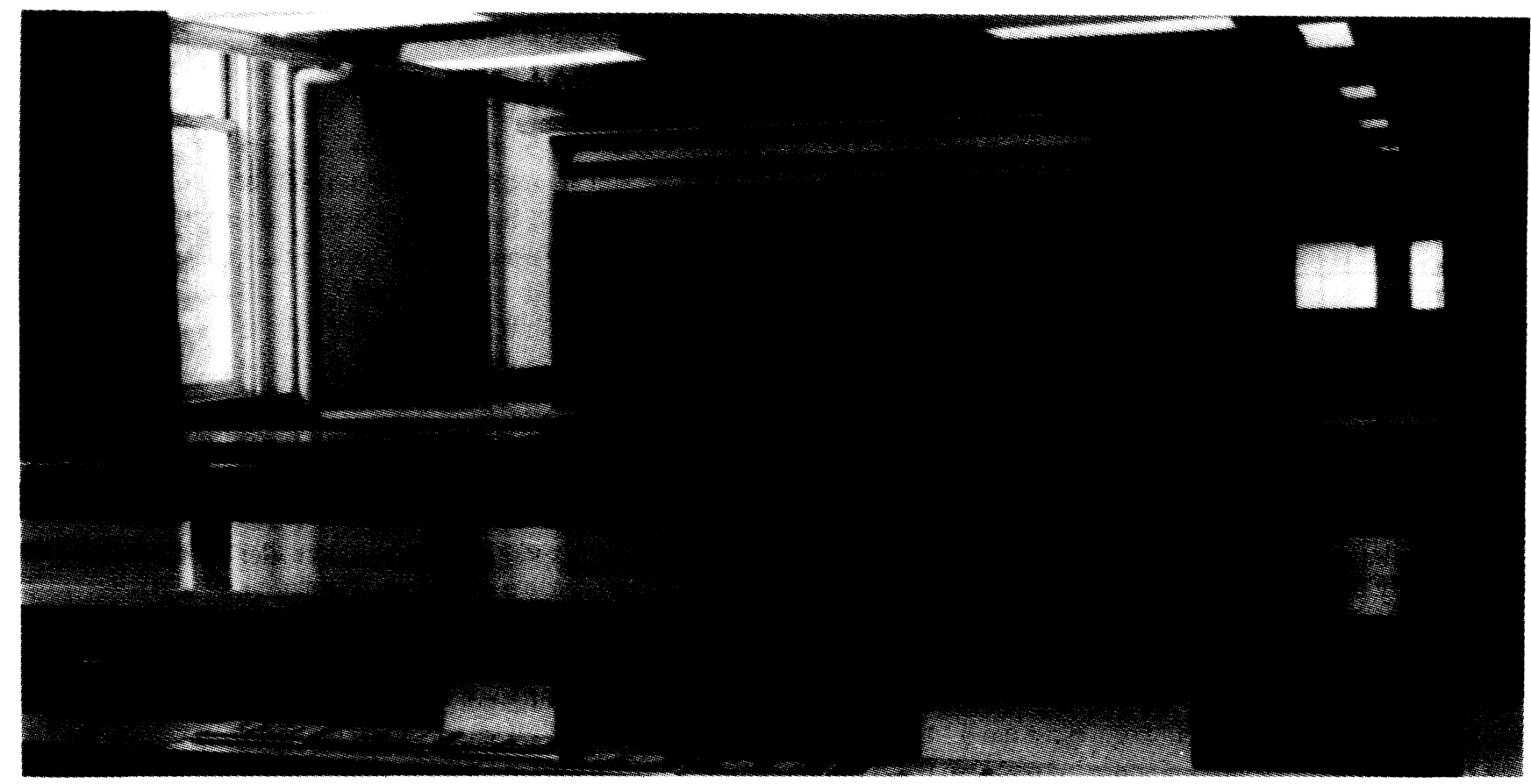

Figure 2 Long light path viewed electronics laboratory.

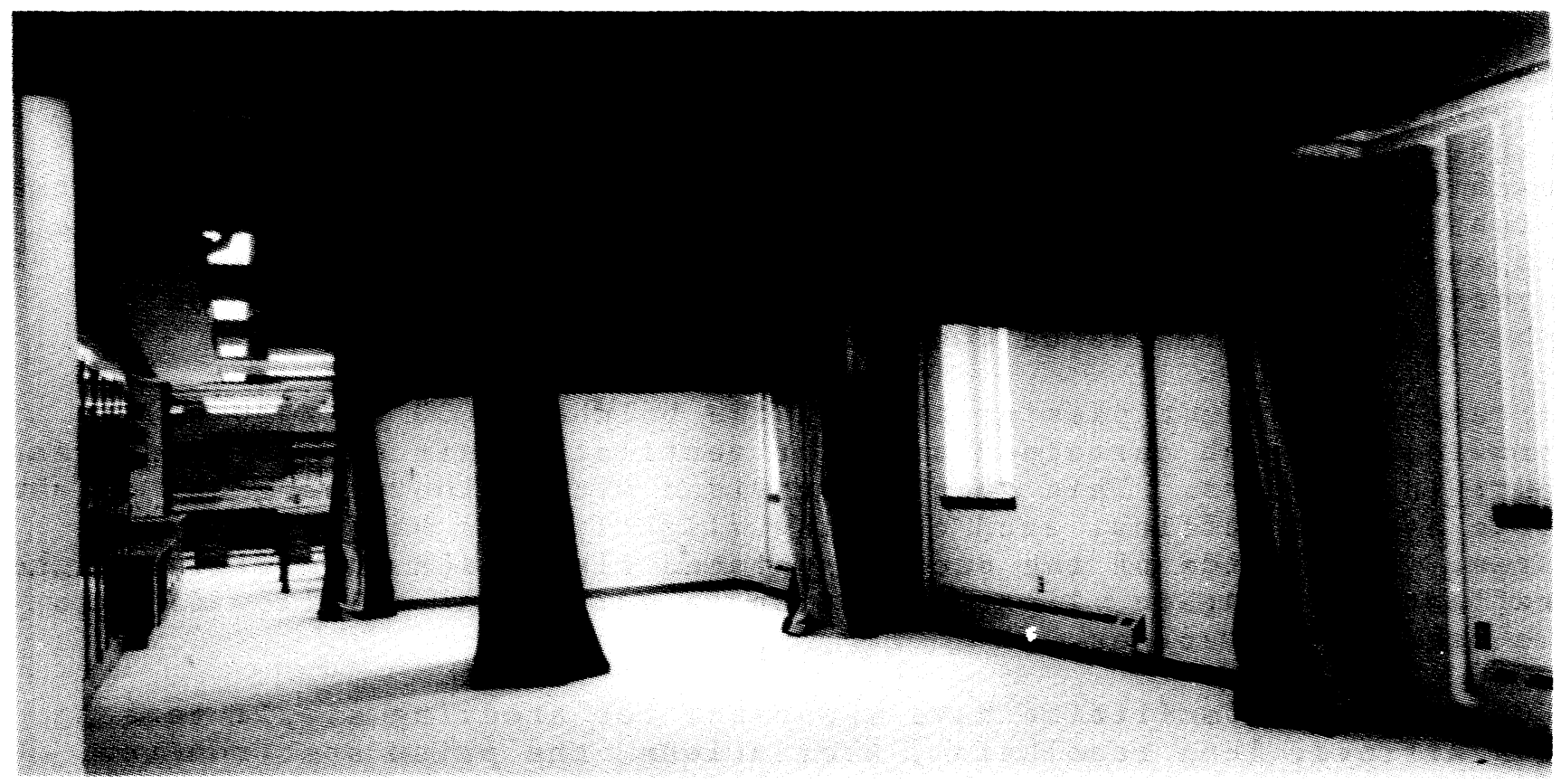

Figure 3 Curtain-walled spaces in optics area. 


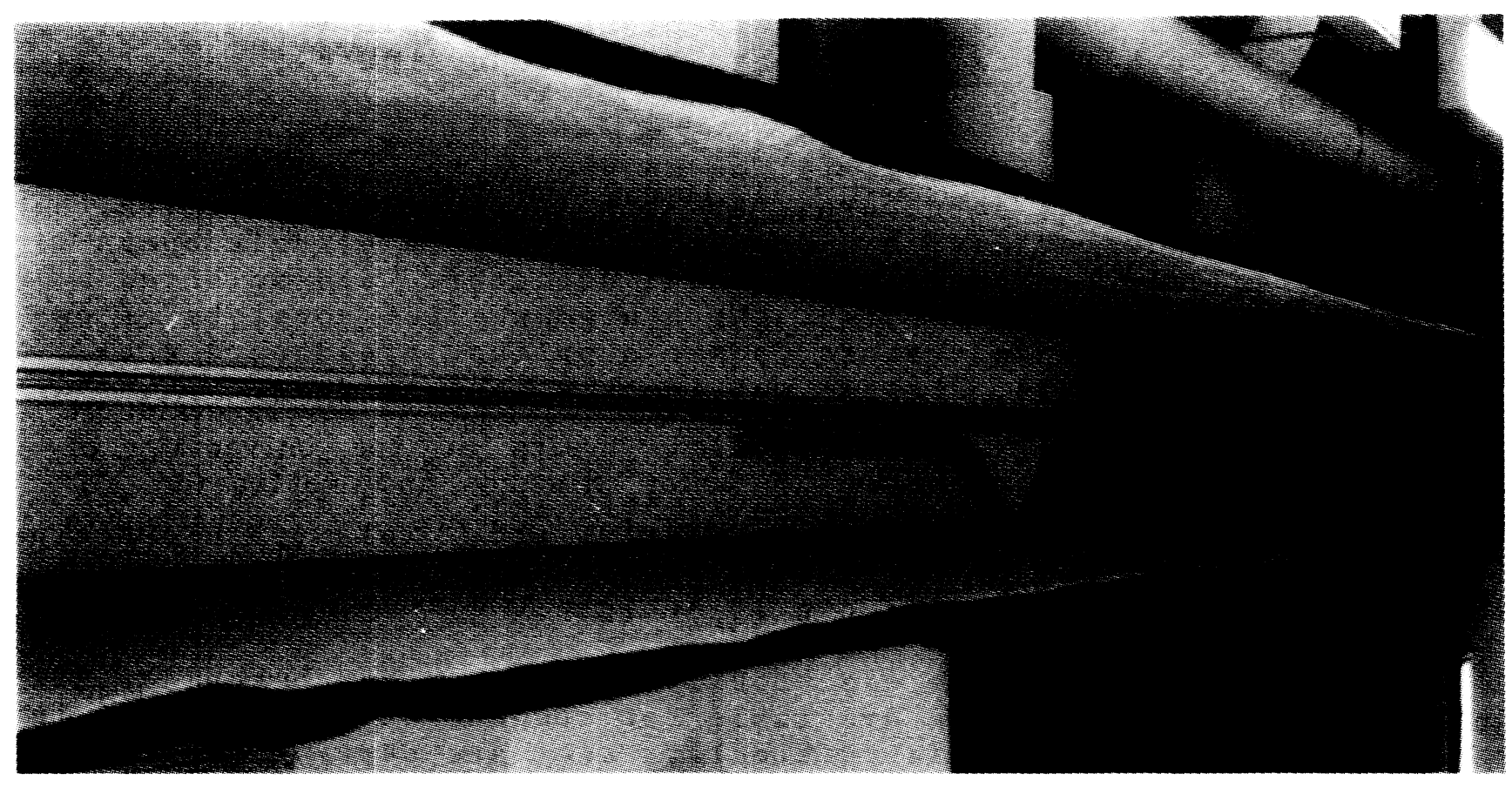

Figure 4 Curtain rail and valances for curtained walls.

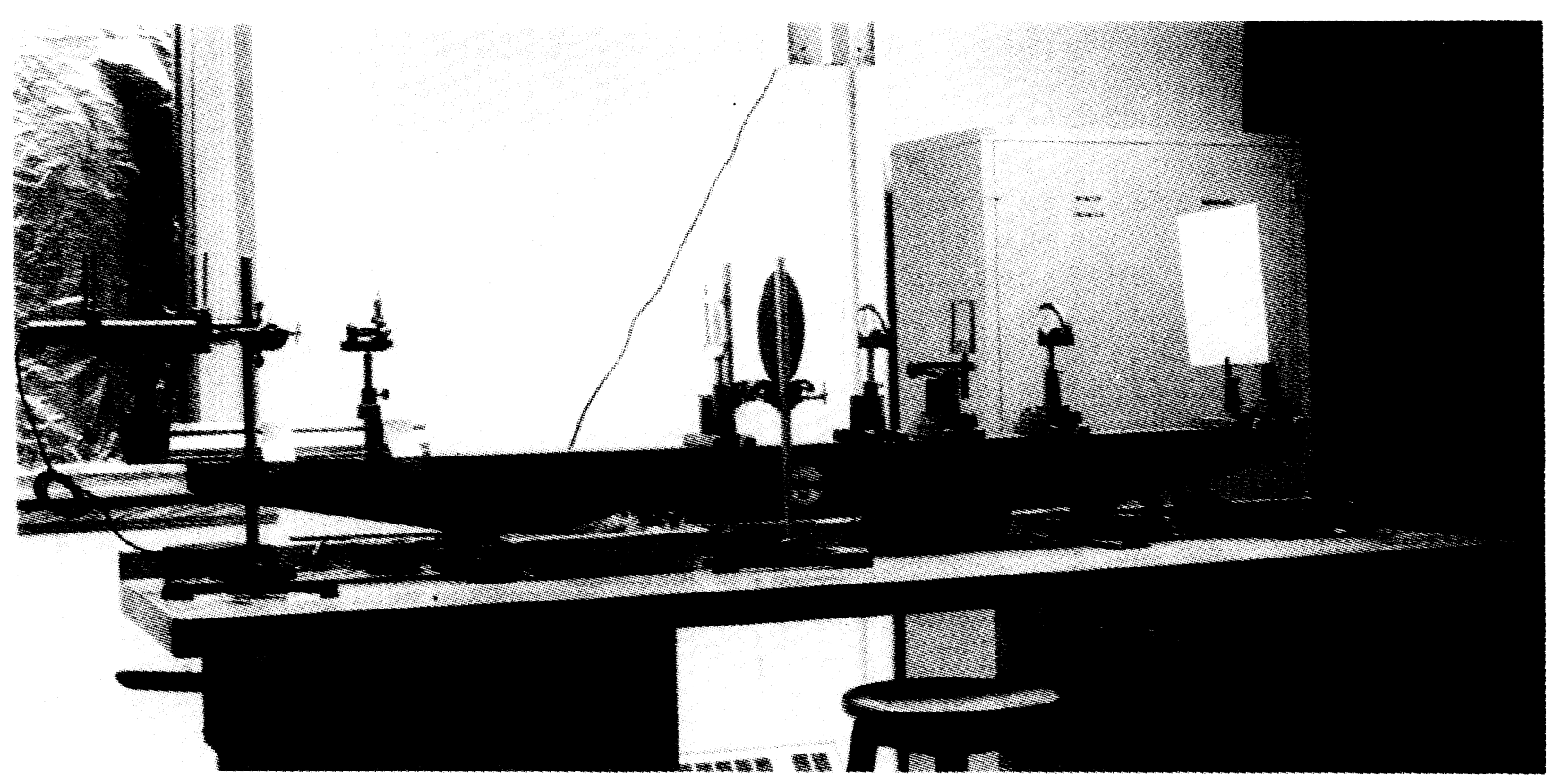

Figure 5 Curtain space with Fourier transform apparatus. 
nitrogen pump laser, a 2 m optical lathe bench, and three vibration isolation tables. In the near future a scanning interferometer is to be purchased for doing Zeeman effect, laser mode studies, and other experiments.

The primary electronics course is set up around the traditional electronics for scientists structure. As such it covers basic circuits, discrete semiconductor device operation, integrated circuit operation, selected electro-optic sources and detectors, and selected applications. Within this format the equipment list consists of oscilloscopes, function generators, power supplies, breadboard stations, frequency meters, digital multimeters, and bridges.

Across the hallway is a large room $(9.3 \mathrm{~m} \times 10.4 \mathrm{~m})$ designed for traditional modern physics laboratory exercises, such as charge-tomass ratio, Millikan oil drop, Frank-Hertz, etc. This space contains four more soft-walled, or curtained, spaces, each about $2.3 \mathrm{~m} \times 3.4 \mathrm{~m}$ for students to control their own light space.

Along the solid wall of the electronics space is a bench top for six computer terminals that are available for student and faculty use in research and coursework. In particular, they are part of the equipment used for the remote sensing and image processing courses which have a specialized computer facility. This facility, adjoining the electronics laboratory, includes an elevated floor, separate regulated power and cooling supplies as well as a halon extinguishing system. The design of this facility is an integrated part of the optics, electronics, electro-optics, and computer simulation modeling program activities. Within this laboratory facilityl are two MicroVAX II computer systems and an I2S digital image display system. The MicrovaX computers are ethernetted to a university computer center VAX cluster and run VMS version 5.4. One MicrovaX supports the I2S image processing system. The other is to provide testing, research, and development through computer simulation modeling in the areas of physics, engineering technology, and computer science involving machine vision, machine sensor systems, expert MRPII+ (advanced manufacturing resource planning), and MRPII neural networking. The university computer center VAX cluster and MicrovAX II's have available the LAS software systems from the National Aeronautics and Space Administration/Goddard Space Flight Center, software systems from DEC, and other software systems in residence. The VAX cluster is networked to disparate computer locations in the state and national/international gateways. A component of computer simulation modeling, the remote sensing/image processing courses are team taught in a cooperative venture with faculty members from several departments and colleges.

\section{PROGRAM PROJECTIONS}

The Physics Department has been asked to consider a degree program in applied physics at the M.S. level. This could extend scientific and technical opportunities within the region to developing engineering technology programs emphasizing flexible computer integrated manufacturing systems (FCIMS) ${ }^{2}$. Thesis problems would likely be con- 
centrated in sensor systems, computer simulation modeling, process control for industrial applications, and image processing for machine vision applications. The prospects for industrial internships and foreign exchange experiences are already being pursued. It is envisioned that joint appointments of faculty from various disciplines, departments, and colleges with the University of West Virginia would be involved in team teaching and project development. Adjunct professor appointments from government and industry would also be involved in the teaming process.

\section{SUMMARY OF RESULTS AND CONCLUSIONS}

Over the past decade an integrated approach to team teaching and facilities development have been accomplished. The new facilities provide a much needed foundation for the final integration phases to a multidiscipline approach in problem solving. A phase of this approach includes the evolution of a plan and its implementation involving optics, electronics, electro-optics, and computer simulation modeling studies. The physical layout of these facilities support integration for studies in a multidiscipline format. This has been accomplished within a limited space by designing for multiple, integrated use for each study discipline. This cooperative approach provides a foundation for further interaction involving the University of West Virginia system and partnerships with industry and government. This enhances the opportunity for further academic, technological and economic development.

\section{ACKNOWLEDGEMENTS}

The authors gratefully acknowledge the generous support of the Speaker of the House, Charles "Chuck" Chambers and the President of the Senate, Keith Burdette, of the West Virginia Legislature who arranged for the acquisition of the two Microvaxil computers and the I $2 \mathrm{~S}$ image display system. This was achieved in cooperation with the Digital Equipment Corporation.

\section{REFERENCES}

1. Ralph Oberly and James 0. Brumfield, "Illustrating Physical Principles through Comparative Feature Extraction Techniques in Optical and Digital Image Processing," SPIE Proceedings, Education in Optics '91, Leningrad, USSR, 1991

2. James 0. Brumfield, Randall L. Jones, Frederick J. Michel and Ralph E. Oberly, "Development of a Strategic Implementation Plan for an Institute for Flexible Computer Integrated Manufacturing Systems," Final Technical Report to National Institute of Standards and Technology, Washington, D.C. Submitted by Marshall University Research Corporation, 1989. 